\title{
Esfera, otredad e individualidad en la obra pictórica de Ofelia Andrades*
}

\author{
Tomás Peters \\ Birkbeck, University of London \\ tpeter03@mail.bbk.ac.uk
}

\begin{abstract}
Resumen
El presente artículo reúne algunos apuntes filosóficos sobre la obra pictórica de la artista chilena Ofelia Andrades. A partir de sus composiciones visuales y alegorías pictóricas, se discuten brevemente las nociones de esfera, individualidad y otredad. El artículo se propone desarrollar una interpretación abierta de las formas de representación del yo -y del "otro social" - en la sociedad contemporánea. Al hacerlo, se enfoca en describir cómo la cotidianeidad y los espacios humanos configuran individualidades en permanente autorreflexión.
\end{abstract}

Palabras clave

Esfera, individualidad, otredad, pintura, Ofelia Andrades.

Sphere, otherness and individuality in the pictorial work of Ofelia Andrades

\begin{abstract}
This article gathers several philosophical notes on the pictorial work of the Chilean artist Ofelia Andrades. By taking Andrades's allegorical paintings and visual compositions, it discusses briefly the notions of sphere, individuality and otherness. This article proposes an open interpretation of the forms of representation of the "I" -and the "social other" - in the contemporary society. In doing so, it describes how the daily life and the human spaces set up individualities in a permanent self-reflexivity.
\end{abstract}

Keywords

Sphere, individuality, otherness, painting, Ofelia Andrades.

\section{Esfera, alteridade e individualidade no trabalho pictórico de Ofelia Andrades}

Resumo

O presente artigo reúne algumas notações filosóficas sobre a obra pictórica da artista chilena Ofélia Andrades. A partir de pinturas alegóricas e composições visuais de

\footnotetext{
* Recibido: 14 de marzo de 2017/ Aceptado: 9 de octubre de 2017.
} 
Tomás Peters. Esfera, otredad e individualidad en la obra pictórica de Ofelia Andrades.

Andrades, se discute brevemente as noções de esfera, individualidade e alteridade. 0 artigo propõe a construção de uma interpretação aberta das formas de representação do "eu" e do "outro social" na sociedade contemporânea. Ao fazê-lo, se enfoca em descrever como o cotidiano e os espaços humanos configuram a individualidade em uma de permanente autorreflexão.

\section{Palavras-chave}

Esfera, individualidade, alteridade, pintura, Ofelia Andrades. 
Los encuentros sociales son espacios privilegiados para producir y contener experiencias sensibles en los individuos. En cada encuentro fortuito o regulado, el sujeto gestiona un sitio donde poder ejercer su estatus como ser humano en el mundo. Peter Sloterdijk ha denominado ese lugar como esfera. Según sus postulados, la pregunta sobre nuestro "dónde" tiene más sentido que nunca,

(...) puesto que se dirige al lugar que los hombres crean para tener un sitio donde poder existir como quienes realmente son. Ese lugar recibe aquí el nombre de esfera, en recuerdo de una antigua y venerable tradición. La esfera es la redondez con espesor interior, abierta y repartida, que habitan los seres humanos en la medida en que consiguen convertirse en tales (Sloterdijk, 2003: 36-37).

Visto así, habitar en esferas significa reforzar, por un lado, ese lugar que permite alojar seres humanos y, por otro, sentar las bases fundamentales de la solidaridad humana. Así, es al interior de múltiples esferas donde la intimidad del ser humano no sólo se desenvuelve y reformula, sino también donde se protege y contiene. En efecto, en las esferas -esos ambientes y atmósferas sociales compartidas- se ponen en juego las muchas y diversas maneras en que la vida humana se constituye como tal. La existencia es siempre acompañada por un otro que promueve intimidades, así como también solidaridades y distancias; es más, en una sola mirada, dos rostros pueden poner a prueba sentimientos de entendimiento y de frustración. Y eso es, justamente, la importancia de las esferas sociales: en ellas se producen los reconocimientos y afiliaciones, así como también los rechazos y las diferencias.

Como ha señalado la filósofa chilena Carla Cordua,

La intimidad humana que le interesa analizar a Sloterdijk en relación con los espacios habitados por grupos no es nunca, como en el caso de Heidegger, la exclusivamente mía encaminada hacia mi propia muerte. Sino que es, más bien, una que incluye contactos y coincidencias con muchos y diversos otros que, compenetrados entre sí, forman complejos núcleos de vida común. Ser un sujeto o un individuo es estar integrado en una de esas esferas de experiencia que sobrepasan en varias direcciones los límites de la persona singular (Cordua, 2008: 176-177).

Entonces, los vínculos, las coincidencias y los intercambios sociales que emergen en una esfera de experiencias se conforman por diversos otros que establecen un mundo en común, pero siempre en potencia de diferencia. El otro funciona entonces como un provocador de intimidades en un doble sentido: por una parte, promueve una comunidad de sentidos donde lo común-familiar se interioriza como seguridad y reforzamiento de mi individualidad. Pero, por otro lado, el otro genera enemistades y desacuerdos que gatillan incomodidades y aislamientos necesarios para el yo. En su conjunto, ambas provocaciones son imprescindibles para el ser humano. La esfera, por su metáfora circular, nos recuerda entonces 
que es el ser humano el centro y los otros su límite: los otros son tanto la distancia que nos envuelve como esa idéntica distancia del centro.

Sin embargo, tanto al interior de la esfera como en su exterior, el individuo experimenta diversos sentimientos y permanentes experiencias. Y esto no significa, en absoluto, que todas estas sensibilidades sean beneficiosas para su trayectoria vital. Por el contrario, en la actualidad pareciera ser que los seres humanos vivimos en una radical desorientación. Lo imaginable se ve enfrentado, casi a diario, por lo inimaginable, y lo real por lo irreal. Bajo la globalización cultural, como nunca antes en la historia vivimos la instantaneidad de la información. El desborde de acontecimientos del horror -atentados suicidas, desplazamientos humanos forzados, invasiones militares, etc.- parecieran hacernos retrotraernos a ese espacio de lo íntimo y permanecer en la seguridad de lo íntimo. En su libro El arte agotado. Magnitudes y representaciones de lo contemporáneo, el filósofo Sergio Rojas expone esta condición humana en forma precisa:

El individuo es el lugar hacia donde la subjetividad está siendo relegada, subsumida en los procesos de magnitud irrepresentable que hoy condicionan la existencia de los hombres. Producto de un paulatino desencanto, escepticismo, desesperanza, nos vamos transformando en lúcidos espectadores de la realidad. Es decir, cambiamos fe y compromiso por lucidez y suspicacia. De un lado, pareciera que la individualidad es una conquista, pero de otro se nos presenta como el rincón al que vamos siendo relegados. Son las dos caras de lo que se denomina individualismo (Rojas, 2012: 43).

Para Rojas, el individualismo es una actitud que se elabora y ejerce en lo cotidiano. Es más, "podría considerarse paradójicamente como una forma de ubicarse en el mundo cuando ya no se puede comprender" (43). Es ahí, según el filósofo, donde la subjetividad se repliega: a saber, hacia la interioridad del espectador que se limita a consumir, observar y vivenciar imágenes de lo real. Y es en la pintura, en este caso, donde las imágenes de lo real-cotidiano pueden aportar a pensar el fenómeno de la intimidad dentro de una comunidad.

Las tensiones entre esferas sociales, otredad e individualidad se pueden representar y pensar desde variadas maneras y formas. Una de ellas es a través de la pintura de la artista chilena Ofelia Andrades. Sus pinturas enuncian una sumatoria importante de problemas estéticos y filosóficos que aportan a esta discusión: el proceso de la pintura, la sociabilidad, el movimiento, la parodia fotográfica, el sí mismo, la otredad. El motivo recurrente de Ofelia Andrades es el oficio pictórico, así como la espontaneidad de los encuentros sociales, por una parte, y sus consecuencias en la propia individualidad, por otra. En efecto, sus composiciones pictóricas esbozan momentos festivos cargados de expresividades faciales, movimientos corporales e interacciones sociales, junto a preparaciones ficticias -y repetidas- de ella misma. Las pinturas, además, hacen mención directa al gesto fotográfico contemporáneo propiciado por la tecnología: la toma espontánea e 
ilimitada, sin costo y despojada de control lumínico. Andrades, al elegir para su trabajo pictórico una fotografía sin su estatuto moderno de la pose artificial, busca destacar el oficio de la pintura desde una pose paródica. En sus trabajos no hay frivolidad ni pereza argumentativa, sino que, por el contrario, hay un esfuerzo consciente por componer técnicamente -capa por capa, tono por tono-aquellos momentos aparentemente inútiles de las esferas sociales, así como sus consecuencias posteriores en la intimidad propia. Y lo hace desde una propuesta específica: siempre dejando en claro o en evidencia que tanto la pintura como la vida espontánea es incompleta o está siempre en proceso.

En sus palabras,

Todas las partes que componen un cuadro presentan problemas distintos, desde la composición, la atmósfera, el espacio y los detalles que quiero resaltar como las caras, las manos, la representación tridimensional. En este último punto me empeño mucho en compensar los aspectos espaciales y tridimensionales que no registra la fotografía. En mis pinturas me gustaría incluir los cinco sentidos para evocar algo de la realidad. (...) Además, son escenas que incluyen retratos que por lo general son sonrisas. Hay muy pocos pintores en la historia que lo han logrado, sobre todo por lo complejo que es capturar esa espontaneidad... (Sumado a ello), me gusta dejar los cuadros inconclusos en ciertas partes, sin que pierdan su carácter de pintura, porque conservan las primeras ideas del boceto, el inicio del proceso creativo. Rescatar el proceso me permite reflexionar sobre la pintura como pintura, como construcción, como técnica, como material (Andrades, 2014: 5-6).

Representar la esfera interior como proceso es, entonces, una de las características de la propuesta pictórica de Andrades.

En la serie Variaciones sobre un mismo tema (exposición en Sala Gasco, 2014), Andrades propone una serie de composiciones numeradas que trabajan con la noción de encuentro y esfera. Así, por ejemplo, en "Composición número 5. Baile de despedida" (2012) es posible advertir una escena cargada de festividad, baile, movimiento, miradas, voces e intercambios comunicativos ${ }^{1}$. El recuadro expone, empero, no sólo un juego de poses y posiciones humanas: es, también, un ejercicio pictórico deslumbrante. Si bien el flash de la cámara digital destaca los cuerpos en su interacción humana, es el tratamiento pictórico dado a la carne, los pliegues y los gestos corporales lo que también produce una fascinación especial en la pintura. "Composición número 5" destaca, así, la interacción de esas pieles y gestos: en ella hay confianza, intimidad y lazo emotivo. Es en esa esfera donde se produce el encuentro entre los seres humanos. Es ahí donde hay miradas íntimas y también cubrimientos de ojos; hay voces desenvueltas y silenciamientos voluntarios;

\footnotetext{
${ }^{1}$ Imágenes que nos recuerdan a la fotógrafa norteamericana Nan Goldin, por ejemplo, en Philippe H. and Suzanne Kissing at Euthanasia, New York City, 1981.
} 
hay cuerpos conectados y rostros indiferentes. La pintura de Andrades busca tematizar entonces que las esferas son tanto encuentros congeniados como espontáneos, tanto conectados como distanciados. Algo similar ocurre en "Composición número 15" (2013). En esta pintura, Andrades selecciona una conversación cualquiera entre tres individuos. A primera vista, el recuadro nos hace pensar en la obvia cercanía emocional entre ellos. Sobre aquello, por cierto, no es posible advertir cuestionamiento alguno. Sin embargo, lo interesante del cuadro es que devela cómo, en un instante -ese segundo fotográfico-, la fragilidad de lo íntimo se revela como desafío al sí mismo. En efecto, las miradas de los individuos se dirigen hacia horizontes contradictorios entre sí. Aun cuando la esfera está completamente lograda -un instante de vida en común-, el individuo se ve compelido a pensar su posición sensible en la esfera social. Los otros que acompañan al individuo sirven, en este caso, como un promotor de intimidad, debido, en parte, a la existencia casi imperceptible-y necesaria- de reconocimientos e indiferencias.

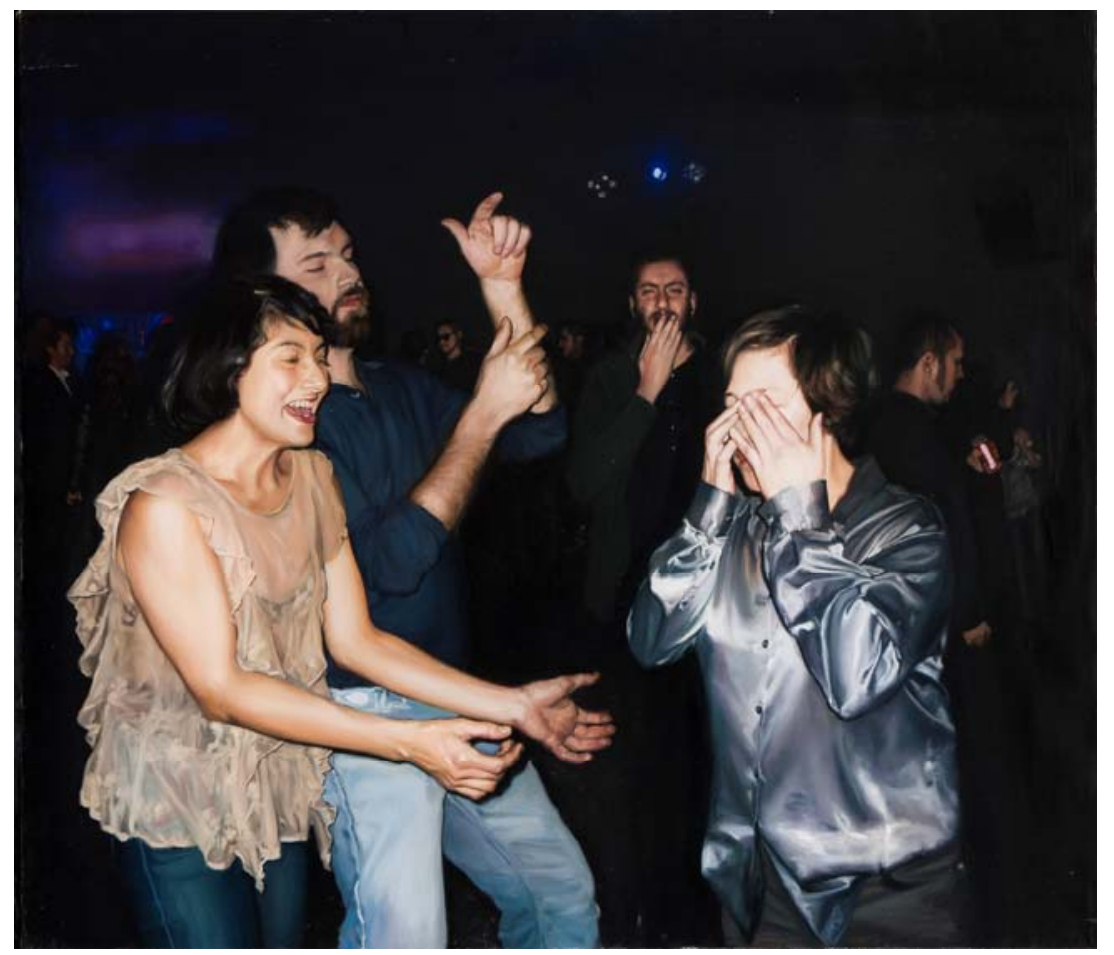

Figura 1. "Composición número 5 -Baile de despedida". Óleo sobre tela, 85 x 96 cm. 2012. 


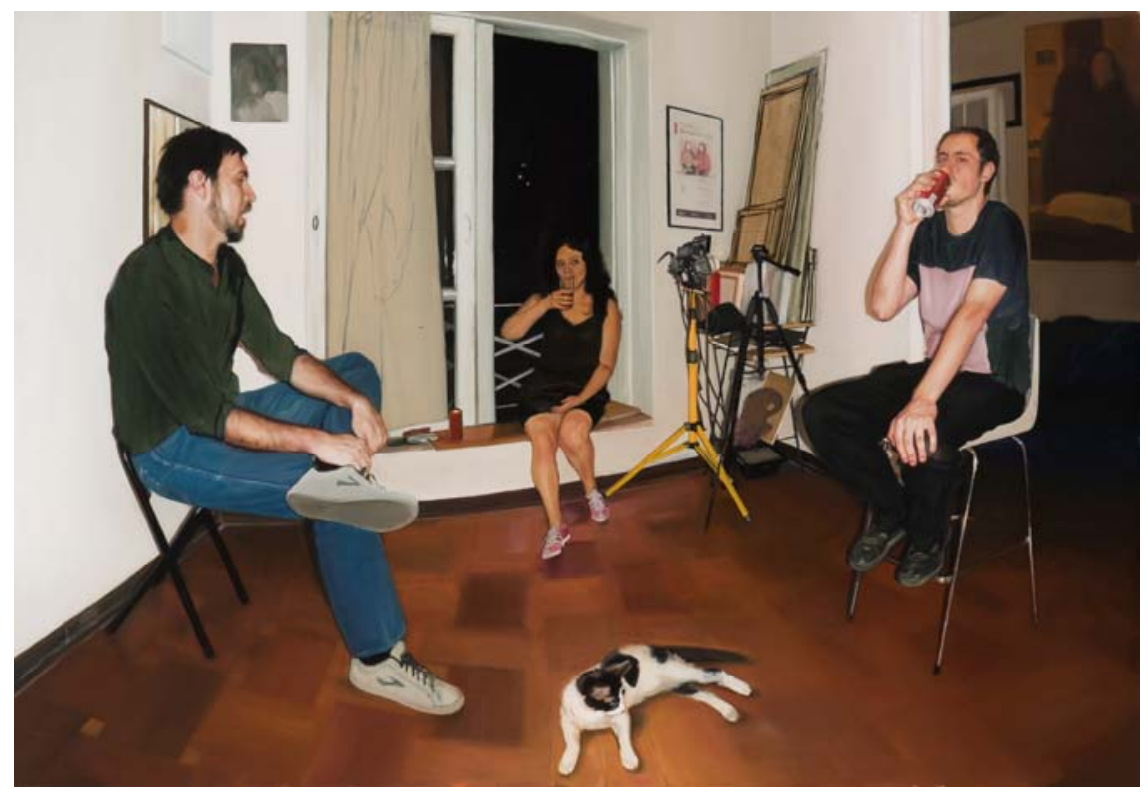

Figura 2. "Composición número 15". Óleo sobre tela, 100 x 145 cm. 2013.

Las teorías de la identidad han señalado claramente que la construcción del sí mismo necesariamente supone la existencia de "otros" cuyas opiniones, miradas e ideas internalizamos. Y lo hacemos en un doble sentido. Por un lado, todo individuo busca en su esfera inmediata un "otro de significancia": un otro que reconocemos como valioso, digno de imitar y, sobre todo, significativo para mi autoimagen. Pero, por otro lado, también somos permanentemente interpelados por "otros de oposición": aquellos que no queremos ser y que poseen costumbres e ideas que acentúan nuestra diferencia. Es en la interacción entre estos dos "otros" donde se constituye el sí mismo. Como ha señalado el sociólogo Jorge Larraín:

El medio social, que se expresa en alemán por el término Umwelt, no sólo nos rodea, sino que también está dentro de nosotros. En este sentido no podría decir que las identidades vienen de afuera en la medida que son la manera de cómo los otros nos reconocen, pero vienen de adentro en la medida que nuestro autoreconocimiento es una función del reconocimiento de los otros que hemos internalizado (Larraín, 2001: 29).

Las esferas, por ende, son un espacio privilegiado no sólo para vivir en relación con ambos otros, sino que, sobre todo, para pensar mi propia intimidad e identidad. Al alejarse de las esferas -siempre por periodos breves-, el individuo tiene un tiempo valioso para procesar, formular y definir las múltiples y diversas formas 
de identidad que el mundo ha puesto a disposición. En un mundo cada vez más caótico, contingente y desintegrado, la individualidad se ve interpelada a pensar los múltiples yo posibles y a ejercer el derecho al testeo íntimo de cada uno de ellos.

Este gesto es especialmente visible en "Alegorías II" (2016). En esta composición pictórica, Ofelia Andrades se auto-retrata cinco veces en variadas poses, gestos, ocupaciones y vestimentas, y además incluye a un otro(a) retratado(a) dos veces. Luego de los encuentros regulados o espontáneos -esas esferas donde se interrelacionan tantos otros significativos como de oposición-, el sí-mismo tiene una ocasión breve pero imprescindible para poder experimentar con las voces, miradas y silencios recopilados en el espacio compartido. A partir de lo vivido en comunidad, el individuo puede crear y exhibir un nuevo e inédito formato del símismo, pero siempre en presencia de un otro (imaginario, aunque siempre presente). De esta forma, para exponerlo en las esferas, debió previamente haber trabajado en la intimidad (al modo de un work in progress) las opciones posibles experimentadas en lo público. Así, al definir una identidad posible, el yo se pondrá a prueba en una nueva esfera y recibirá nuevos estímulos que cambiarán su estatuto individual, y así sucesivamente hasta el infinito.

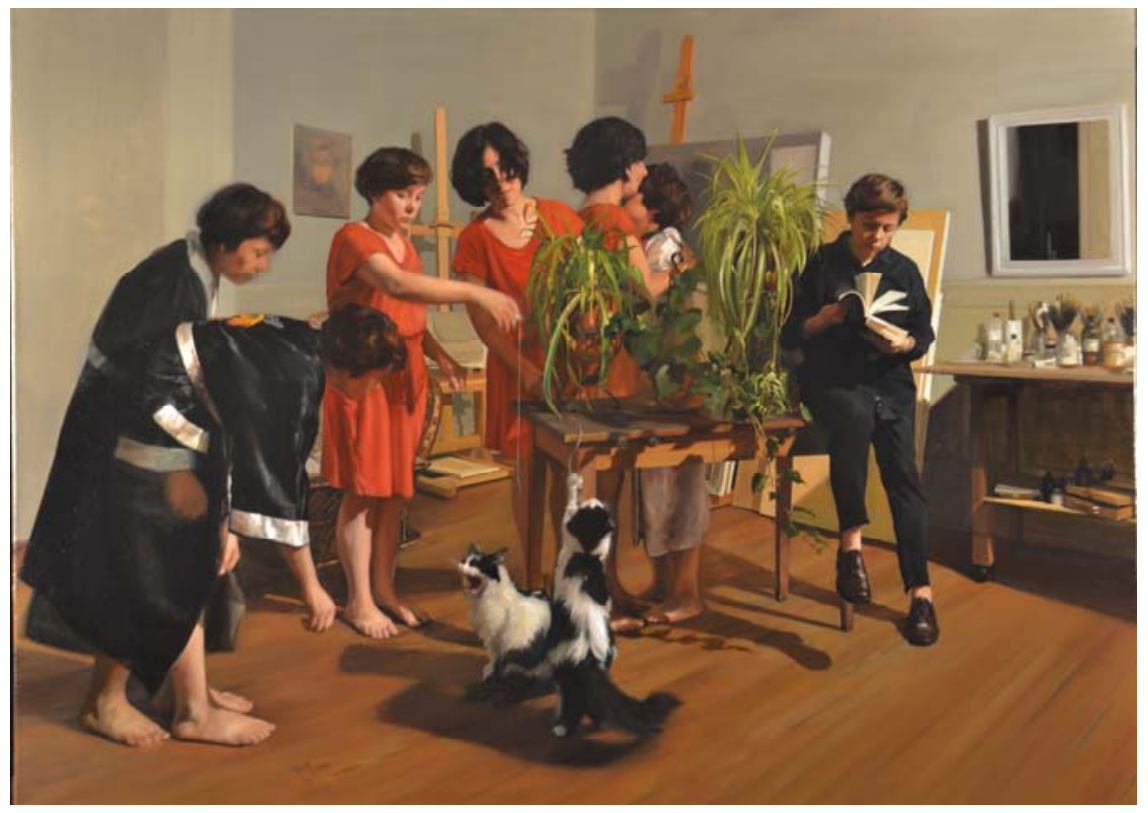

Figura 3. "Alegorías II". Óleo-resina sobre lino. 115 × 160 cm. 2016. 
En definitiva, en "Alegorías II" Andrades representa en varios sí-mismos el espacio vivido. Pero, a diferencia de la serie anterior de "Composiciones", la representación no es espontánea (como las fotografías instantáneas y acumulables hasta el infinito): es, por el contrario, artificial, compuesta, construida -como la autoreflexividad misma. Efectivamente, en la intimidad no hay espacio para lo aleatorio o lo impensado. Al interior de "Alegorías II", como al interior de la intimidad, los procedimientos, gestos y actitudes son meditados y conformados según decisiones conscientes. En este sentido, Andrades compone una escena teatral con múltiples yuxtaposiciones de imágenes de un sí-mismo en permanente reconstrucción y alteración. Pero lo hace siempre incluyendo un otro presente.

En base a ello, es posible advertir que no hay una realidad unificada, integrada y sin conflictos: por el contrario, tanto en las esferas como los momentos íntimos el ser humano constituye un sitio - un espacio de refugio- donde poner a prueba nuevos rostros, diversas vestimentas, otras ocupaciones y múltiples sentimientos. Así como las espumas se dispersan en múltiples direcciones y poseen una fragilidad extrema, el ser humano se va trasladando de esferas en esferas y de otros en otros frágilmente. $Y$ en todos estos encuentros el individuo se ve compelido a transformarse y repensarse en presencia de/con otros de significado y otros de oposición. La pintura de Ofelia Andrades explora entonces lo que nos rodea y lo que nos interpela en el mundo interior. Y lo hace con el oficio de la pintura al descubierto. En su trabajo no hay un montaje tecnológico, sino una parodia fotográfica que busca deslumbrar la manualidad como gesto técnico irrepetible.

\section{Referencias}

Andrades, O. (2014). Variaciones sobre un mismo tema. Santiago: Galería Gasco.

Cordua, C. (2008). Sloterdijk y Heidegger. La recepción filosófica. Santiago: UDP.

Larraín, J. (2001). Identidad Chilena. Santiago de Chile: LOM.

Rojas, S. (2012). El arte agotado. Magnitudes y representaciones de lo contemporáneo. Santiago: Sangría.

Sloterdijk, P. (2003). Esferas I. Burbujas. Microsferología. Madrid: Siruela. 